\title{
Meiosis of Dihaploid Thelypteris decursive-pinnata Produced Artificially by Induced Apogamy
}

\author{
Suzue M. Kawakami ${ }^{1 *}$, Juntaro Kato ${ }^{2}$ and Shogo Kawakami ${ }^{2}$ \\ ${ }^{1}$ Nishio Nursing College, Togasaki, Nishio City, Aichi 445-0074, Japan \\ ${ }^{2}$ Department of Biology, Aichi University of Education, Igaya, Kariya City, Aichi 448-8542, Japan
}

Received June 25, 2019; accepted July 16, 2019

\begin{abstract}
Summary Dihaploid Thelypteris decursive-pinnata $(2 n=2 x=60)$ was produced artificially from tetraploid $T$. decursive-pinnata $(2 n=4 x=120)$ by induced apogamy. In the spore mother cells of dihaploid sporophytes, many bivalent chromosomes (maximum 30 bivalents) and some univalent chromosomes were observed at metaphase I. Lagging chromosomes were frequently observed at anaphase I and anaphase II, and in most of the sporangia many young normal and abnormal spores were observed. The meiotic chromosome behavior might indicate that the donor $T$. decursive- pinnata is autotetraploid.
\end{abstract}

Key words Apogamy, Autotetraploid, Meiosis, Thelypteris decursive-pinnata.

Haploid plants have been produced artificially by induced apogamy in ferns (Whittier and Steeves 1960, 1962, Kawakami et al. 1995, 1996, 1997). These haploid plants induced become very important materials for investigating the origin of ferns since ferns have been considered to be developed by chromosome doubling and hybridization (Manton 1950, Wagner 1954, Lovis 1977). In our previous studies, from the meiotic chromosome observations of haploid Osmunda japonica (Kawakami et al. 2003) and haploid Woodwardia prolifera (Kawakami et al. 2019) showing all univalents at meiotic metaphase I, the base chromosome number was confirmed to be $x=22$ and $x=34$, respectively. In dihaploid sporophytes such as Pteris multifida (Kawakami et al. 1995), P. dispar (Kawakami et al. 1996), P. semipinnata (Kawakami et al. 1996) and W. orientalis (Kawakami et al. 2019), whether their donor plants are autotetraploid or allotetraploid was investigated from the meiotic chromosome pairings. It takes a long time for haploid sporophytes induced to grow until the development of leaves with sporangia and the time is different from sporophyte to sporophyte. In the present study the dihaploid T. decursive-pinnata induced produced fertile fronds. Then, the meiosis of dihaploid sporophytes was observed. The chromosome number of T. decursive-pinnata was reported to be $n=30$ (Mitui 1968, Hirabayashi 1969, Masuyama 1979), $n=60$ (Mitui 1968, Hirabayashi 1969, Masuyama 1979), 2n=60 (Masuyama 1986, Kurizono 1987), $2 n=90$ (Mitui 1967) and $2 n=120$ (Kurizono 1987). In the present study sporogenesis of the donor sporophyte was observed to confirm the chromosome number to be $n=60$ (i.e., $2 n=120$ ) and to compare the

\footnotetext{
*Corresponding author, e-mail: fernkawa@mb.ccnw.ne.jp DOI: $10.1508 /$ cytologia.84.319
}

sporogenesis of haploid sporophytes induced with the donor. The comparison of relative DNA contents and guard cell sizes between donor and dihaploid sporophytes were also carried out here.

Materials and methods

Spores of T. decursive-pinnata (van Hall) Ching collected in Oita Pref., Japan, were used for axenic culture. Surface-sterilized spores of $T$. decursive-pinnata were sown on 1/4 strength of Murashige and Skoog (1962) medium supplemented with $3 \%$ sucrose and $0.9 \%$ agar. Cultures were illuminated by a fluorescent lamp (FL-

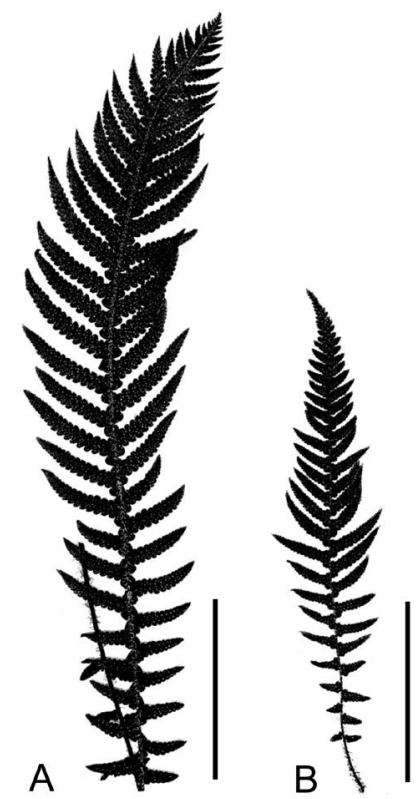

Fig. 1. Fronds of T. decursive-pinnata. A: Donor tetraploid sporophyte. B: Apogamously produced dihaploid sporophyte. Scale bars $=10 \mathrm{~cm}$. 


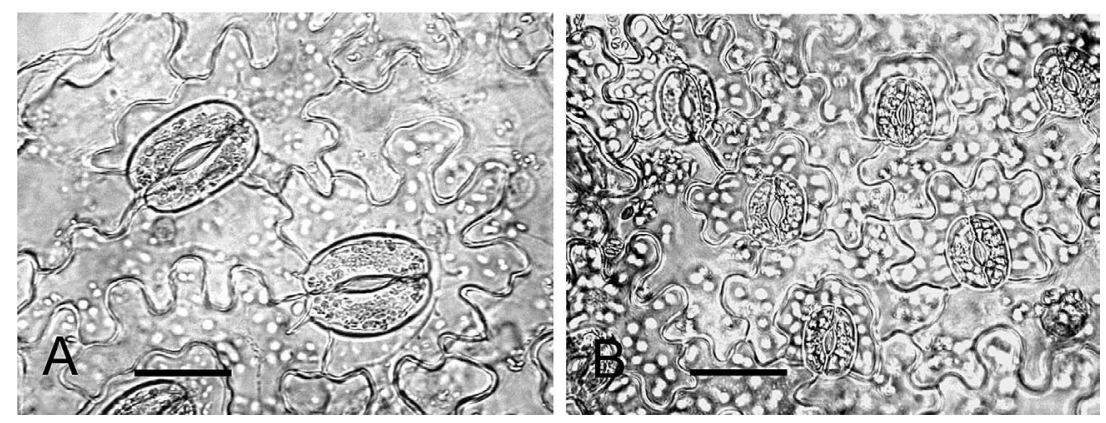

Fig. 2. The comparative guard cells of the donor tetraploid sporophyte and the apogamously produced dihaploid sporophyte in $T$. decursive-pinnata. A: Donor tetraploid sporophyte. B: Apogamously produced dihaploid sporophyte. Scale bars $=40 \mu \mathrm{m}$.

$15 \mathrm{BR}, \mathrm{NEC}$ ) for $12 \mathrm{~h}$ per day at $25^{\circ} \mathrm{C}$. The sporophytes raised from gametophytes without fertilization were grown on agar until they developed roots. Then plants were transferred into pots. The sporophytes developed fertile fronds have been cultivation in pots. Meiotic chromosomes were observed by fixing sporangia with $3: 1$ ethanol-acetic acid for $30 \mathrm{~min}$ at $5^{\circ} \mathrm{C}$ and squashing them in $2 \%$ aceto-orcein solution. The DNA contents of nuclei in fronds were estimated by flow cytometry using a Partec Ploidy Analyzer PA (Partec Münster, Germany) (Kawakami et al. 2003).

\section{Results}

Although the fronds of apogamously produced sporophytes in $T$. decursive-pinnata were smaller than those of the donor tetraploid sporophyte, the sporophytes produced resembled the donor plant (Fig. 1). The mean size of 100 guard cells was $47.5 \mu \mathrm{m}$ in the donor sporophyte and $32.4 \mu \mathrm{m}$ in the apogamously produced sporophyte. The guard cell sizes in the sporophyte produced apogamously showed to be significant $(T<0.01)$ (Fig. 2).

Relative DNA contents of nuclei between the apogamously produced sporophytes and the donor sporophyte were investigated. The DNA contents of apogamously produced sporophytes showed approximately half of the donor T. decursive-pinnata (Fig. 3).

Meiosis of the donor $T$. decursive-pinnata was observed (Fig. 4). In the spore mother cells, 60 bivalents were observed at metaphase I (Fig. 4A) and two nuclei were formed by chromosome separation (Fig. 4B). After the second meiotic division four nuclei were formed and then tetrad spores were produced (Fig. 4C). In sporangia, many spores (up to 64) were observed (Fig. 4D).

Meiosis of the apogamously produced sporophytes was observed (Fig. 5). In the spore mother cells, many bivalents and some univalents were frequently observed at metaphase I (Fig. 5A). Thirty bivalents in maximum, though rare, were observed (Fig. 5B). The lagging chromosomes were frequently observed at anaphase I (Fig. 5C) and anaphase II. Tetrad spores were observed (Fig. 5D). Dyad spores were rarely observed (Fig. 5E). Although many young spores were produced, in most of

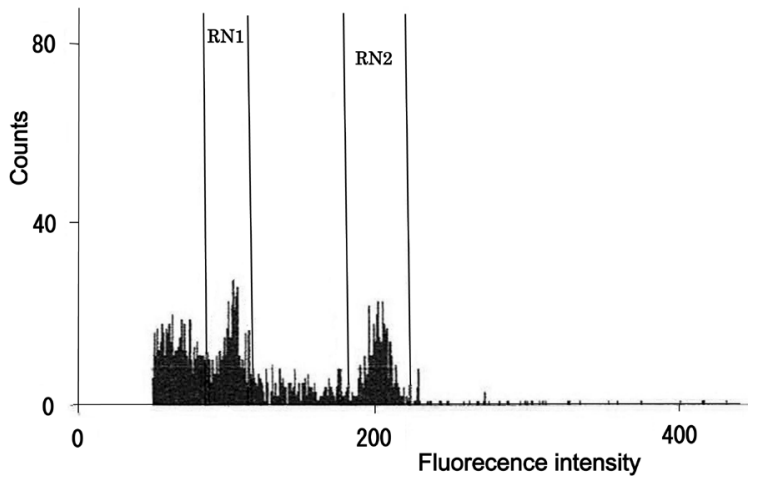

Fig. 3. DNA contents of the apogamously produced dihaploid sporophyte (RN1) and those of the donor tetraploid sporophyte (RN2) in $T$. decursive-pinnata. Histograms represent the number of nuclei per fluorescence intensity (arbitrary units).

the sporangia abnormal spores were observed (Fig. 5F).

\section{Discussion}

From the observation of meiotic chromosome behaviors, it was confirmed that the donor sporophyte is $n=60$ (i.e., $2 n=4 x=120$ ) and the apogamously produced sporophyte is $n=30$ (i.e., $2 n=2 x=60$ ). The chromosome number of donor tetraploid sporophyte with $2 n=4 x=120$ in $T$. decursive-pinnata was coincident with the studies reported by several authors (Mitui 1968, Hirabayashi 1969, Masuyama 1979, Kurizono 1987). The induction of dihaploid sporophyte with $2 n=2 x=60$ from tetraploid T. decursive-pinnata was reported here for the first time and the apogamously produced sporophytes were haploid was also shown from the relative DNA content by using flow cytometry in the present study.

Polyploidy is associated with increases in stomatal lengths is known (Takahashi 1962, Kawakami et al. 2017). In the case of $T$. decursive-pinnata, the guard cells of dihaploid sporophyte showed to be smaller than the donor tetraploid sporophyte $(T<0.01)$.

To know the origin of tetraploid sporophytes meiotic chromosome pairing is useful. Lots of bivalents in the dihaploid sporophyte might indicate that the donor tetraploid is autotetraploid and lots of univalents in the dihaploid sporophyte might indicate that the donor tetraploid 

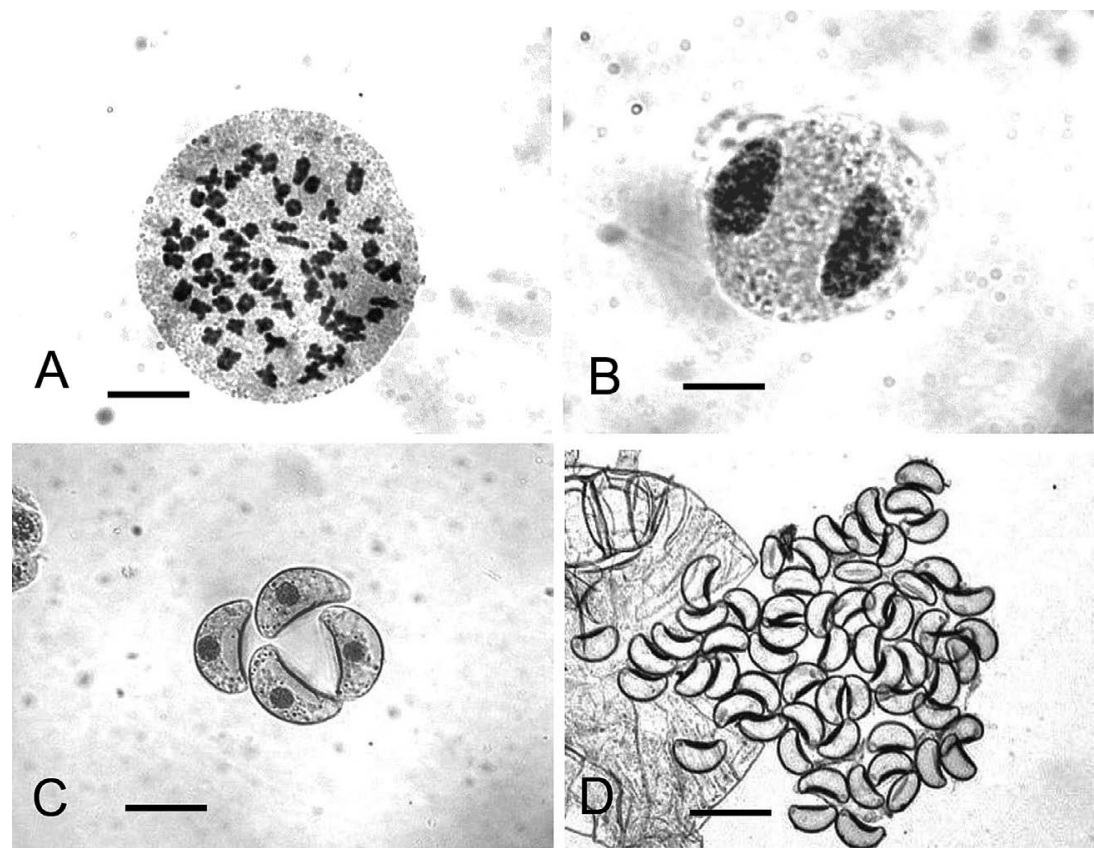

Fig. 4. Meiosis of the donor tetraploid T. decursive-pinnata. A: Meiotic cells with 60 bivalents at metaphase I. B: Two nuclei formed after the first meiotic division. C: A tetrad. D: Many spores produced in a sporangium. Scale bars $=10 \mu \mathrm{m}(\mathrm{A}, \mathrm{B})$, $25 \mu \mathrm{m})$, and $50 \mu \mathrm{m}(\mathrm{D})$.

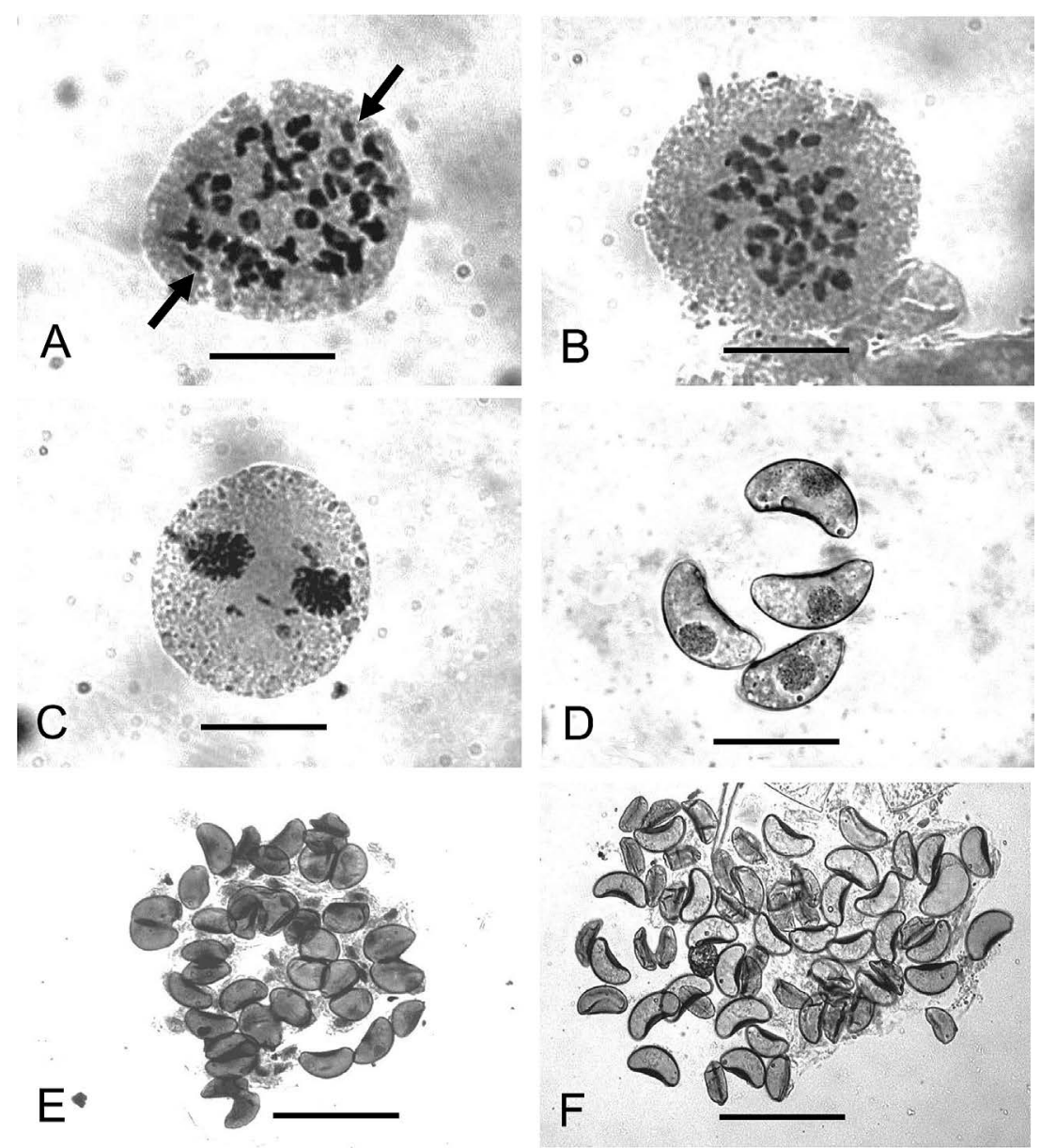

Fig. 5. Meiosis of the apogamously produced dihaploid T. decursive-pinnata. A: Meiotic chromosomes with 29 bivalents and two univalents at metaphase I. Arrows indicate univalent chromosomes. B: Meiotic chromosomes with 30 bivalents at metaphase I. C: Chromosome separation with lagging chromosomes at anaphase I. D: A tetrad. E: Dyads produced in a sporangium. F: Many young normal and abnormal spores produced in a sporangium. Scale Bars $=10 \mu \mathrm{m}(\mathrm{A}-\mathrm{D})$ and $50 \mu \mathrm{m}$ (E, F). 
is allotetraploid originated from chromosome doubling of a hybrid. In the previous study from the observation of meiotic chromosome behavior of two dihaploid Pteris species produced by apogamy, we concluded that $P$. semipinnata with $2 n=116$ is allotetraploid, whereas $P$. dispar with $2 n=116$ is autotetraploid (Kawakami et al. 1996). In the present study, it might be considered that the donor $T$. decursive-pinnata with $2 n=120$ is autotetraploid from the observation of 30 bivalents in the apogamously produced dihaploid sporophytes though in most of sporangia abnormal spores were observed. That is because in spore mother cells with 30 bivalents fertile reduced spores might be produced, however, in spore mother cells with univalents the meiosis might be performed irregularly by the univalent chromosomes and abnormal spores without fertility might be produced. From the observation of dyads, a few fertile unreduced spores might be produced in dihaploid sporophytes. It might be necessary to investigate the DNA contents of fertile spores.

\section{References}

Hirabayashi, H. 1969. Chromosome numbers in several species of the Aspidiaceae. Shokubutsu Kenkyu Zasshi 44: 185-1192.

Kawakami, S. M., Ito, M. and Kawakami, S. 1995. Apogamous sporophyte formation in a fern Pteris multifida and its characteristics. J. Plant Res. 108: 181-184.

Kawakami, S. M., Ito, M. and Kawakami, S. 1996. Induced apogamous sporophytes in Pteris dispar and P. semipinnata, and the meiotic behavior in their sporocytes. J. Plant Res. 109: 369-379.

Kawakami, S. M., Ito, M., Kawakami, S. and Kondo, K. 1997. Induction of apogamy in twelve fern species and the study of their somatic chromosomes. Chromosome Sci. 1: 89-95.
Kawakami, S. M., Kawakami, S., Kondo, K., Kato, J. and Ito, M. 2003. Sporogenesis in haploid sporophytes of Osmunda japonica (Osmundaceae). J. Plant Sci. 164: 527-534.

Kawakami, S. M., Kawakami, T., Kato, J. and Kawakami, S. 2019. Meiotic chromosome behaviour of apogamously produced haploid sporophytes in Woodwardia orientalis and W. prolifera. Fern Gaz. 21: 35-41.

Kawakami, T., Kato, J. and Kawakami, S. M. 2017. Meiosis of autotetraploid Osmunda banksiifolia produced by induced apospory and the DNA contents of spores produced. Chromosome Bot. 12: $7-12$.

Kurizono, S. 1987. Cytological studies on some taxa in thelypteroid ferns, Aspidaceae. Kromosome II 46: 1513-1520.

Lovis, J. D. 1977. Evolutionary patterns and processes in ferns. Adv. Bot. Res. 4: 229-415.

Manton, I. 1950. Problems of Cytology and Evolution in the Pteridophyta. Cambridge University Press, Cambridge.

Masuyama, S. 1979. Reproductive biology of the fern Phegopteris decursive-pinnata I. The dissimilar mating systems of diploids and tetraploids. Bot. Mag. Tokyo 92: 275-289.

Masuyama, S. 1986. Reproductive biology of the fern Phegopteris decursive-pinnata II. Genetic analyses of self-sterility in diploids. Bot. Mag. Tokyo 99: 107-121.

Mitui, K. 1967. Chromosome studies on Japanese ferns (3). J. Jap. Bot. 42: 105-110.

Mitui, K. 1968. Chromosomes and speciation in fern. Sci. Rep. Tokyo Kyoikudaigaku. Sec. B. 13: 285-33.

Murashige, T. and Skoog, F. 1962. A revised medium for rapid growth and bioassays with tobacco tissue culture. Physiol. Plant. 15: 473-497.

Takahashi, C. 1962. Cytological study on induced apospory in ferns. Cytologia 27: 79-96.

Wagner, W. H. Jr. 1954. Reticulate evolution in the Appalachian Asplenium. Evolution 8: 103-118.

Whittier, D. P. and Steeves, T. A. 1960. The induction of apogamy in the bracken fern. Can. J. Bot. 38: 816-826.

Whittier, D. P. and Steeves, T. A. 1962. Further studies on induced apogamy in ferns. Can. J. Bot. 40: 1525-1531. 